\title{
Normatização e relações de poder nas atas do Concílio de Coyanza
}

Andreia Cristina Lopes Frazão da Silva*

Resumo: O Concílio de Coyanza foi realizado em meados do século XI na diocese de Oviedo, durante o reinado de Fernando I e Sancha, em Castela-Leão. Esta assembleia é considerada por muitos autores como uma das mais importantes reunidas na península Ibérica durante o medievo. É citada em diversos trabalhos, mas desde 1950 não foram realizados estudos específicos e sistemáticos sobre as suas atas conciliares. Tais atas foram transmitidas por diversos manuscritos, que contém duas redações com diferenças formais e de conteúdo, o que propicia ao historiador discutir questões relacionadas à circulação e transmissão de tais materiais. Neste artigo, a partir da análise das referidas atas e de reflexões historiográficas já elaboradas sobre tal assembleia, discuto aspectos da normatização no Reino Castelhano-leonês no período e de sua difusão manuscrita, relacionando-as às relações de poder.

Palavras-chave: Concílio de Coyanza. Reino de Castela-Leão. Normas. Poder. Difusão manuscrita.

\section{Introdução}

O Concílio de Coyanza foi realizado em meados do século XI, na diocese de Oviedo, durante o reinado de Fernando I e Sancha, então reis de Castela e Leão. ${ }^{1}$ Esta assembleia é considerada por muitos autores como uma das mais importantes reunidas na Penín-

\footnotetext{
* Professora-Associada IV do Departamento de História da UFRJ, atuando junto ao Programa de Pós-Graduação em História Comparada. É uma das coordenadoras do Programa de Estudos Medievais da UFRJ. Pesquisa financiada pelo CNPq. E-mail: andreiafrazao@terra.com.br.
} 
sula Ibérica durante o medievo (MARTÍNEZ, 1973, p. 543; MENDO CARMONA, 2005, p. 124; AYALA MARTÍNEZ, 2008, p. 276) e é citada em diversos trabalhos (FERNÁNDEZ DEL TORCO, 1943; LINAGE CONDE, 1995; DÍAZ DE GARAYO, 1997; SANZ SANCHO, 1998; SÁNCHEZ CANDEIRA, 1999, p. 126128; LÓPEZ ALSINA, 2002; CALLEJA PUERTA, 2006; MINGUEZ, 2007; BANGO TORVISO, 2011). Entretanto, ainda que mencionadas em vários estudos sobre esta reunião, os testemunhos desta reunião foram pouco estudados como objeto específico.

Da reunião foram transmitidas duas versões das atas, que possuem diferenças formais e de conteúdo. Este aspecto, longe de significar um problema, pode suscitar novas questões, pois considero que as atas de Coyanza são um testemunho crucial para a compreensão das relações de poder entre eclesiásticos e monarcas castelhano-leoneses nos séculos XI e XII, bem como para discutir as estratégias de disciplinamento social que se buscaram implantar por meio de tais normativas. Neste artigo, a partir da análise das duas redações das referidas atas, bem como das reflexões historiográficas já elaboradas sobre tal material, discuto aspectos da normatização no Reino Castelhano-leonês no período e de sua difusão manuscrita.

As ideias aqui apresentadas resultaram do desenvolvimento da pesquisa Monacato, poder e gênero: reflexões sobre o cenóbio de San Millán de La Cogolla em perspectiva diacrônica (1076-1109/1227-1265), realizada com o financiamento do CNPq e finalizada em fevereiro de 2013. A meta central era comparar e discutir como se constituíram e operaram, nas diversas relações sociais e de poder estabelecidas pela comunidade monástica de San Millán de La Cogolla, as construções de gênero. Para tanto, analisei e comparei textos hagiográficos, normativos e notariais que foram produzidos e/ou circularam em dois períodos da história desse cenóbio - o primeiro, de 1076 a 1109 , e o segundo de 1227 a 1265. Dentre os textos investigados, encontram-se as atas do Concílio de Coyanza. ${ }^{2}$ 


\section{As atas de Coyanza: estudos edições e transmissão manuscrita}

Os principais estudos sobre o Concílio de Coyanza datam de meados do século passado e foram publicados em duas obras consideradas ainda hoje referenciais. A Miscelánea Comemorativa Del Concilio de Coyanza, de 1951, reuniu os trabalhos apresentados no evento que comemorou os novecentos anos da referida assembleia, ocorrido em 1950. Tais textos tinham como temáticas principais a transmissão dos decretos de Coyanza, a datação da assembleia, a relação entre as tradições visigodas e as normas aprovadas e a interpretação de alguns decretos, como os referentes à vida canônica e à liturgia. ${ }^{3}$

No mesmo ano da realização da reunião comemorativa, veio a público um estudo crítico sobre o Concílio de Coyanza realizado por Garcia Gallo, que ainda é considerado o trabalho mais importante já composto e o mais citado sobre o documento em tela. Publicado como artigo no Anuario de historia del derecho español, o estudo de 359 páginas reúne os principais debates historiográficos desenvolvidos até então sobre a assembleia de Coyanza; aborda os manuscritos e as edições das atas; discute sobre a data de celebração do concílio, a natureza da reunião, as motivações para sua convocação; analisa, a partir das atas, o que denomina como doutrina do concílio, e publica os registros da assembleia, indicando as variações entre os manuscritos (1950, p. 358-359). Por sua análise exaustiva e seu caráter de síntese, este é o principal trabalho com o qual dialogamos.

As atas do Concílio de Coyanza já foram alvo de várias publicações desde o século XVII, contudo, uma edição crítica das mesmas ainda não foi realizada. Segundo Garcia Gallo (1950, p. 278), até o momento em que ele realizou sua pesquisa, não havia sido realizado um inventário completo dos manuscritos que transmitiram tais atas. Durante a minha investigação, não encontrei notícias sobre um levantamento de todos os manuscritos dos decretos de Coyanza. Neste sentido, acredito que o quadro mantém-se o mesmo desde 1950.

Garcia Gallo apresenta cinco códices das atas conciliares em seu artigo: o Livro Gótico ou Liber testamentorum de Oviedo, datado entre 1126-1129 (O); o manuscrito de Toledo, fragmentado, do século XVI (T); o manuscrito de Córdoba, de data incerta, mas que foi 
publicado em 1601, por C. Baronio (C); um manuscrito encontrado e divulgado por Pellicer de Ossau y Tovar, em 1681 (P), e o Livro Preto de Coimbra, cartulário formado entre os séculos XII-XIII (LP). ${ }^{4}$ Faz-se importante destacar que, além desses manuscritos, os decretos de Coyanza estão contidos em outros códices, que também transmitem o Fuero de León (VAZQUEZ DE PARGA, 1944, p. 475-478).

Todos esses manuscritos possuem variantes, contudo, é possível agrupá-los em dois conjuntos. No primeiro grupo, encontra-se o LP. No segundo, O, T, C e P. O critério usado para esta divisão é o fato de que esses manuscritos apresentam duas redações diferentes das mesmas atas. Garcia Gallo defendeu que O, T, C e P tiveram o mesmo protótipo, atualmente perdido (1950, p. 320), ainda que tenham sido copiados de forma independente. Para Vazquez de Parga, este manuscrito-modelo foi elaborado entre 1050-1120 e continha, além dos decretos de Coyanza, o Fuero de León (1944, p. 474). O LP provém de outra tradição textual. Segundo uma nota presente no manuscrito, ${ }^{5}$ estes decretos teriam sido levados para o mosteiro de Vacariça por Randulfo, um dos monges desta comunidade que teria assistido à assembleia, e dali chegaram à diocese de Coimbra. Garcia Gallo acata como verídica esta informação e ainda destaca que não era uma prática comum no século XI fazer cópias das decisões de uma reunião para difundi-las em todo o reino, provavelmente devido ao alto custo. Assim, eram os próprios assistentes que se encarregavam de fazer cópias, para serem levadas consigo ao retornarem às suas regiões de origem (1950, p. 305).

O texto das atas de Coyanza transmitido pelo LP, denominado por Garcia Gallo como $A$, foi publicado pela primeira vez por Mansi, no Supplementum ad collectionem conciliorum et decretorum, em 1774, e durante quase dois séculos foi considerado uma falsificação. Só a partir da década de 1940 que esta redação passou a ser considerada como a mais próxima do que seria o texto original das atas de Coyanza.

Dentre o segundo conjunto de manuscritos, Garcia Gallo destaca $\mathrm{O}$, que é o mais antigo do grupo e compõe o Liber Testamentorum Ecclesiae, uma compilação realizada em Oviedo, durante o governo de Pelayo, que foi prelado entre 1102 a 1130, e, posteriormente, em 1142 e 1143 . Este período, como destaca Raquel Alonso Álvarez, "[...] coincide con unos momentos especialmente delicados para la 
diócesis de Oviedo, cuya independencia se veía amenazada por las pretensiones anexionistas toledanas" (2007-2008, p. 24).

A cidade de Oviedo, após a expansão muçulmana na península, foi a capital do reino de Astúrias e sucedeu Toledo, sob domínio islâmico, na direção da Igreja Hispana. Contudo, com a expansão cristã em direção ao sul, no início do século $\mathrm{X}$, a capital foi transferida para a cidade de Leão, nome pelo qual o reino passou a ser conhecido, e, em 1085, Toledo conquistada. Oviedo passou a ocupar um papel secundário e periférico no quadro político e eclesiástico do reino castelhano-leonês. A ampla produção literária promovida por Pelayo tinha como meta, portanto, aumentar o prestígio de sua diocese e assegurar os direitos da sede ovetense, o que explica o grande número de falsificações e interpolações que, segundo os especialistas, foram produzidas no scriptorium episcopal (FERNÁNDEZ CONDE, 1971, p. 193-197, p. 197-199, p. 215218 , p. 235-238). Dentre os muitos materiais copiados, como já destacado, encontra-se uma versão das atas de Coyanza.

Estaria, portanto, na prática das falsificações e interpolações que eram realizadas na sede diocesana de Oviedo a explicação para as duas versões textuais das atas de Coyanza? Garcia Gallo defende que não. Para o autor, a fama de "poca escrupulosidad" de Pelayo não pode ser levantada como argumento definitivo para explicar as diferenças redacionais dos decretos, salvo se o protótipo de O, T, C e P tenha se originado no scriptorium ovetense, o que não é possível verificar, visto que o mesmo, como já assinalado, perdeu-se (1950, p. 321). Sem dúvida, não se trata de um argumento definitivo, mas plausível, em face de tradição de interpolação da escola episcopal de Oviedo sob Pelayo.

Garcia Gallo denomina como texto $B$ o que é transmitido pelos manuscritos $\mathrm{O}, \mathrm{T}, \mathrm{C}$ e $\mathrm{P}$, ainda que estes possuam pequenas variantes. Esta versão foi a primeira e mais difundida redação dos decretos de Coyanza e considerada, durante séculos, como o texto autêntico das atas, que teria sido transmitido sem interpolações ou cortes.

Nas duas redações, as atas apresentam duas partes: um prefácio e treze cânones, que no texto B são chamados de títulos, que normatizam sobre temas diversos. O I trata da vida canônica; o II aborda aspectos da vida regular; o III versa sobre a autoridade epis- 
copal, a eucaristia, a aparência dos clérigos, a proibição destes portarem armas e de conviverem com mulheres, a residência de laicos nas igrejas e o ensino da fé cristã para as crianças; o IV institui o dever dos eclesiásticos convidarem os pecadores à penitência; $\mathrm{o} V$ aponta quais conhecimentos eram necessários aos clérigos e qual deveria ser a participação em casamentos e enterros; o VI estabelece os dias em que os fiéis deveriam ir à Igreja e proíbe a convivência com judeus; o VII aborda como os condes e os maiores do Rey deveriam administrar a justiça; o VIII reafirma as disposições do rei Afonso V de Leão para o julgamento de delitos em Leão, Galiza, Astúrias e Portugal e as de Sancho, o Grande de Pamplona, para Castela; o IX trata das propriedades das igrejas; o X aborda a destinação dos frutos cultivados em uma terra sob pleito; o XI institui o jejum às sextas-feiras; o XII instrui sobre o direito de asilo dado às igrejas e, por fim, o XIII reafirma a supremacia da justiça do rei.

Quais são as principais diferenças entre as duas redações? Em primeiro lugar, há que destacar os distintos preâmbulos. Na versão $A$ há um texto pautado em passagens bíblicas, que não figura em $B$, no qual os males que sobrevieram à terra são atribuídos ao esquecimento dos desígnios divinos e é feita uma exortação para que a palavra de Deus seja ouvida. Também há divergências quanto à data de realização da assembleia, aos sujeitos que ordenaram os decretos e ao número de bispos presentes, temas que retomarei adiante.

No tocante aos decretos, há variações de forma e conteúdo. Como sintetiza Garcia Gallo: "[...] en ocasiones, la distinta redacción de un mismo pasaje no afecta a lo dispuesto en él: o [...] la misma norma aparece simplificada o con mayor riqueza de detalles... muchas veces se observa uma distinta regulación de la matéria tratada" (1950, p. 331). As principais diferenças de conteúdo são: o texto $A$ decreta que a vida canônica e o ministério eclesiástico deveria ser organizados, o $B$ só faz menção ao ministério eclesiástico (cânone I). A versão $A$ permite que as comunidades monásticas elejam a regra beneditina ou a isidoriana, enquanto a $B$ ordena que seja seguida somente a de São Bento (cânone II). A proíbe que os monges possuam bens e $B$ não faz referência ao tema (cânone II). Também há diferenças sobre quais ornamentos os diáconos deveriam vestir (cânone III). A redação $A$ omite a referência à pena 
para os laicos que violam o ordenado no cânone III, que, contudo, está presente em $B$ (cânone III). Em $A$ cabe aos abades, junto aos presbíteros, chamar para a penitência, em $B$, aos arquidiáconos e presbíteros (cânone IV). Em $A$ trata-se do batismo e da crisma, tema ausente em $B$ (cânone $\mathrm{V}$ ). Em $A$ é prevista a ordenação de monges, em $B$, só de clérigos (cânone V). Em $A$ é proibida a presença dos monges em núpcias, salvo para abençoar, em $B$, aos presbíteros (cânone V). Em $A$ é recomendado que os laicos presentes nas refeições após a exéquias de um morto ofereçam algum bem por sua alma, em $B$ a norma é tanto para leigos quanto clérigos (cânone V). A fixa em 31 passos o espaço de asilo nas igrejas e prevê multa de 100 soldos e asilo com anátema para quem a violar, $B$ reduz o espaço para trinta passos e prevê multa de 1000 soldos de "purissimi argenti" (Cânone XII).

Por fim, destacam-se duas outras diferenças. A redação $A$ finaliza com o decreto treze e não apresenta uma fórmula final ou confirmação. Em B há uma confirmação do Fuero de Leão dado por Afonso $\mathrm{V}$ de Leão, pai da rainha Sancha, e uma norma de caráter penal, que prevê diversos castigos para quem não cumprir a lei promulgada nos cânones.

\section{Considerações sobre o Concílio de Coyanza a partir das atas transmitidas}

O estudo sobre o Concílio de Coyanza suscita muitas questões, não só porque as atas foram preservadas em duas versões, mas porque não são encontradas notícias sobre esta reunião em textos contemporâneos ao evento. A única referência que pode ser relacionada à assembleia, ainda que indireta, está na Historia Silense, composta por volta de 1110, que afirma que só depois da batalha de Atapuerca, na qual o rei Fernando combateu seu irmão Garcia de Nájera, que ali foi morto, foi garantida a segurança do reino e o monarca pode dedicar-se a combater os mouros e a fortalecer as Igrejas de Cristo: "Fredinandus rex postquam mortuo fratre et cognato [Garsia]... iam securus de patria, reliquum tempus in 
expugnanda barbaros in ecclesias Christi corroborandas agere decrevit", (SANTOS COCO 1921, p. 71).

É importante perceber que este concílio, tão enaltecido pela historiografia dos séculos XX e XXI, não despertou o mesmo interesse em sua época, já que é ignorado por outros textos contemporâneos à assembleia. Este destaque dado à Coyanza pode ser explicado pelas matrizes historiográficas que sustentam distintas interpretações sobre as relações de Fernando I com a Igreja castelhano leonesa, seja para destacar a preeminência da Igreja face ao rei ou para reforçar a interpretação contrária. A seguir, vamos retomar alguns dos pontos estudados por Garcia Gallo em seu longo artigo para melhor compreensão das atas de Coyanza.

Conforme indicam as duas redações das atas, a reunião foi realizada durante o reinado de Fernando I. Filho de Sancho III, o maior, que reuniu sob sua direção os então reinos Astur-leonês, Pamplona, ${ }^{6}$ Aragão e o condado de Castela, Fernando recebeu como herança de seu pai o condado castelhano, enquanto seus irmãos passaram a dirigir outras áreas. ${ }^{7}$ Com a morte de seu cunhado, Bermundo III, rei de Leão, ocupou o trono deste reino em 1038, por estar casado com a herdeira do trono, Sancha, passando a ser intitulado na documentação como rei de Leão e Castela. Segundo Juan Carrasco, Fernando "[...] ejercería el poder durante su vida, pero sería la reina la que reinaria bajo su tutela, como si fuese menor de edad" (2005, p. 111-112). Este dado pode explicar porque os nomes do rei e da rainha figurem em ambas as redações das atas de Coyanza, e não somente o do rei.

Segundo Sánchez Candeira, o reinado de Fernando I e Sancha teve como metas a reorganização interna e a luta contra Pamplona (1999, p. 165). As relações com este reino, onde governava García de Nájera, irmão de Fernando, foram harmônicas até 1052. Contudo, disputas por territórios nas regiões mais orientais de Castela culminaram com a batalha de Atapuerca, já mencionada e redundaram na incorporação de áreas em Bureba e Montes de Oca e das localidades de Herrera, Oña e Poza de la Sal (CARRASCO, 2005, p. 112). Juan Carrasco acrescenta que outro projeto de Fernando I foi a expansão de seu reino em direção às áreas sob 
domínio muçulmano. Dessa forma, além de anexar e colonizar várias regiões, também impôs o pagamento de parias a diversos reinos de taifas, abarcando "[...] desde el frente galaico-portugués, hasta las operaciones que conlleva dar una vuelta de tuerca más sobre él régulo zaragozano y, sobre todo, las estratégias diseñadas en torno a esa punta de lanza contra Toledo" (2005, p. 114).

Todo este labor guerreiro resultou não só em maior prestígio da realeza, mas também em riquezas que, em grande parte, foram utilizadas para construir ou restaurar templos e mosteiros, muitos dos quais haviam sido destruídos no início do século XI durante as campanhas de Almonzor (CARRASCO, 2005, p. 114). Além de tal restauração material, é possível concluir que estes recursos também foram utilizados para fortalecer institucionalmente a Igreja Castelhano-leonesa, em particular a autoridade episcopal. Os bispos, que foram alvo de doações e privilégios, bem como passaram a ocupar diversos papéis na corte real, foram figuras estratégicas fundamentais para a consolidação da ocupação das áreas recém-incorporadas. Nesse sentido, é possível propor que a assembleia de Coyanza foi uma etapa fundamental na politica eclesiástica do rei Fernando I.

Em que momento do reinado de Fernando I e Sancha foi realizada a assembleia de Coyanza? Como já ressaltei, nos textos $A$ e $B$ são apresentadas datas distintas. No $A$, "in era M. ${ }^{a}$ LXXXX. ${ }^{a}$ III. a", ou seja, o ano de 1055, e em $B$, "IN ERA MILESIMA LXXX. ${ }^{\circ}$ VIII. a", 1050. Garcia Gallo opta pela datação presente em $A$, fundamentando-se em alguns argumentos, dos quais destaco aqueles que, em minha opinião, são os mais coerentes e com os quais concordo. ${ }^{8}$ $O$ primeiro é que a datação em $B$ é resultado, provavelmente de um erro do copista, que transformou o último X de LXXXX em $\mathrm{V}$, copiando, portanto, LXXXV. O segundo é a referência presente na Historia Silense, já referenciada, de que Fernando se ocupou da Igreja após a batalha de Atapuerca, ocorrida em 1054. O terceiro baseia-se na lista de bispos presentes na reunião. Comparando os decretos com outros diplomas contemporâneos, não há dúvidas de que todos que lá figuram já ocupavam o posto episcopal em 1055, o que não é possível afirmar em relação a 1050 (1950, p. 344-352). Aceito, portanto, a datação sugerida pelo estudioso: 1055. 
Mas quem convocou esta assembleia e por quais motivações? Para Garcia Gallo (1950, p. 360), nenhuma das redações dos decretos de Coyanza indica quem convocou a reunião, só que o rei estava presente. Para ele, nem a tradição visigótica nem a prática medieval da convocação real de concílios é argumento para defender que a realização da reunião foi iniciativa dos reis.

Vamos aos textos. $\mathrm{Na}$ redação $A$, os narradores das atas são os bispos. Neste sentido, é informado que "[...] temporibus serenissinti atque regis principis domni Fredenandi et coniugis sue domne Sancie regine editum est hoc decretum in Concilio", ou seja, que foi no tempo do reinado de Fernando e Sancha que estes decretos foram ordenados e que as decisões do concílio foram tomadas por consenso dos bispos com os reis ("nos autem episcopi superius noninati consentiente Fredenando rege et Sancia regina"). Já no texto B, o narrador é o próprio rei Fernando, que em primeira pessoa informa: "ego Fredenandus rex et Sancia regina, ad restaurationem nostre Christianitatis, fecimus Concilium in castro Coianka, in diocese scilicet Oventensi, cum episcopis et abatibus et totius nostri regni obtimatibus". A esta introdução segue uma lista de bispos presentes. Em minha interpretação, a redação $B$ parece indicar que o concílio foi uma iniciativa real, ao usar a expressão "fecimus Concilium".

$\mathrm{Na}$ minha opinião, a discussão sobre quem de fato convocou o concílio em tela não é crucial. É perceptível em $A$ e $B$, ainda que possuam estratégias narrativas distintas, que o concílio reuniu e elaborou normas com a participação do rei e dos bispos. Para Garcia Gallo, contudo, esse tema é fundamental, pois defende que a reunião de Coyanza possuía um caráter essencialmente eclesiástico. Assim, para ele, foram os bispos presentes que "[...] desempenaron el papel esencial en la reunion", com "mero consentimento del rey" (1950, p. 361) e por isso seus nomes foram listados. Discordo da interpretação do autor. Primeiro, porque o fato de uma instituição ter sido a convocadora da reunião não significa que ela foi, sozinha, a que impôs todas as decisões. Esta perspectiva ignora as possibilidades de negociação entre os diferentes grupos/ instituições participantes do evento. Em segundo, porque naquela conjuntura somente a realeza teria as condições políticas e econômicas de convocar um concílio com a presença de grande parte 
dos bispos do reino. Como argumentarei adiante, a inclusão do nome dos bispos presentes pode ter outro sentido além de destacar o seu protagonismo nas decisões conciliares.

Intimamente ligado ao tema da convocação, os autores preocuparam-se em discutir a motivação e a natureza da reunião, que também é registrada nos dois textos das atas. Em $A$, destaca-se o caráter de correção e ordenação objetivado pelo concílio, em harmonia com as regras da Igreja e os costumes dos antigos pais (pro corrigendis ac dirigendis regulis vel tramitibus Ecclesie, ut mos est antiquorum patrum). O texto $B$ justifica o concílio pela necessidade de restauração do cristianismo local (ad restaurationem nostre Christianitatis). As interpretações levantadas foram muitas: a assembleia de Coyanza foi uma reunião secular de cortes; uma cúria regia; uma assembleia mista - real e eclesiástica; ou ainda um autêntico concílio de caráter eclesiástico, seguindo a tradição visigoda. ${ }^{9}$ Contudo, creio que esta preocupação em classificar a reunião de Coyanza é anacrônica e tem como referenciais instituições anteriores ou posteriores ao século XI. Assim, encontrar a "real" natureza do encontro torna-se uma questão sem interesse. Nesse sentido, o que podemos concluir pela análise de ambas as redações das atas é que a referida reunião contou com a presença de eclesiásticos e laicos, incluindo o rei e a rainha, dentre os quais ganharam destaque os bispos, cujos nomes são registrados, para discutir questões diversas relacionadas ao cotidiano da Igreja castelhano-leonesa e da sociedade em geral e aprovar normas para todo o reino.

Outra questão que tem sido discutida vinculada ao Concílio de Coyanza é a sua relação com a chamada reforma gregoriana e com a expansão do movimento cluniacense na Hispania. Nesse sentido, além de Garcia Gallo, discutiram o tema Charles Julian Bishko, Hilda Grassotti, Salvador Martínez, António García y García, Faci, Valdeón e García de Cortázar. ${ }^{10}$ Tais obras podem ser agrupadas em dois grandes grupos: aqueles que relacionam Coyanza aos influxos externos de organização eclesiástica, promovidos, sobretudo, por Roma e pelos monges de Cluny, e os que consideram que a assembleia em tela propôs uma restauração da Cristandade castelhano-leonesa pautada unicamente nas tradições hispanas. Tais interpretações devem ser compreendidas à luz do 
que Denis Menjot (2011, p. 213) denomina como “[...] noção de diferença que está implícita ou explicitamente, na origem de numerosos trabalhos, $[\mathrm{e}]$ nutre sentimentos identitários". Dessa forma, ao analisar os decretos de Coyanza, os autores pautam-se na questão da identidade da "Espanha" em relação ao restante da Europa, seja para realçá-la ou rechaçá-la.

Em face de tais interpretações dicotômicas, que opõe "nacional" a "estrangeiro" e "reforma" a "restauração", concordamos com a perspectiva de Sanz Sancho, que propõe a superação dessas interpretações que buscam um único sentido para a assembleia de Coyanza. Como destaca o autor, "[...] los aires de reforma en León y Castilla no eran totalmente importados (de Roma, Cluny, Cataluña, Sur de Francia, etc.), ni totalmente autóctonos" (1998, p. 89). A combinação de influxos diversos fica evidenciada pela própria transmissão em dupla redação das atas conciliares.

Quanto aos presentes, as informações nas duas redações são semelhantes. Em $A$, figuram como assistentes à reunião o rei, a rainha, os abades e os bispos; em $B$, além desses, destaca-se que também estavam presentes os grandes do reino, "et totius nostri regni obtimatibus". ${ }^{11}$ Desse conjunto, porém, só são nominados o casal real e os bispos, o que aponta para uma preponderância dos mesmos na reunião em ambas as redações. Para Garcia Gallo, este destaque dado aos prelados, como já sublinhado, "[...] revela que fueron ellos quienes desempeñaron el papel essencial en la reunión” (1950, p. 361).

Apresento outras possibilidades de interpretação. Em primeiro lugar, os bispos são denominados junto aos reis, porque certamente eram em número muito menor do que os abades e optimates presentes. Em segundo, como os bispos são os diretores das dioceses e estas são as unidades territoriais em que se divide a Igreja, esta enumeração também pode ter sido incluída nas atas como um recurso retórico para realçar a unidade eclesial sob domínio castelhano-leonês. Ou seja, mais do que significar uma preeminência dos bispos, como defende Garcia Gallo, a inclusão desta listagem, em ambas as redações, possuía um caráter simbólico: atestar que toda a cristandade castelhana-leonesa participou do concílio e das decisões ali tomadas. 
As listas de bispos que figuram nas duas redações possuem divergências quanto à ordem e ao número de presentes. No texto $A$, lemos:

In unum cum omnes episcopi convenissent: Petrus videlicet Lucensis metropolis, similiter et Froilani Ovetensis, Cresconius Iriensis et apostolice sedis, Ciprianus Legionensis, Didacus Asturiacensis, Miro Palentinus, Gomice Calagorritanus, lhoanes Panpilonensis, item Gomice Osimensis, Sisnandus Portugalensis.

$\operatorname{Em} B:$

In quo Concilio presentes extitere: Froilanus episcopus Ovetensis, Ciprianus Legionensis, Didacus Astoricensis, Mirus Palentine sedis, Gomezius Occensis, Gomezius Kalagurritanensis, Iohannes Pampilonensis, Petrus Lucensis, Cresconius Iriensis.

Comparando a lista de bispos presentes nas redações $A$ e $B$, são identificadas algumas diferenças significativas que passo a discutir.

O texto $A$ apresenta um nome a mais, o de Sisnandus Portugalensis. Segundo Garcia Gallo, há diplomas datados entre 1049 e 1070 em que consta um Sisnandus episcopus, que, porém, só utiliza a titulação Portugalensis episcopus após 1066 (1950, p. 348). O fato do texto $A$ ter sido copiado e transmitido na região de Coimbra pode explicar a sua inclusão entre os assistentes, já que este é o único nome divergente em relação ao texto $B$. Quanto ao uso do título Portugalensis episcopus, como a cópia da ata certamente foi realizada após 1066, buscou-se indicar o prelado como ele era identificado nos diplomas.

Outra diferença digna de destaque é o fato de que no texto $A$ Iria, que em 1095 foi trasladada para Compostela, figure como uma sé apostólica, por meio do título dado a Crescônio: Cresconius Iriensis et apostolice sedis. A omissão desse título no texto $B$ pode estar ligada às estratégias levadas a cabo pelo bispo Pelayo para aumentar o prestígio e assegurar os direitos da sede ovetense, já assinaladas. Afinal, Iria reivindicava um papel de destaque devido ao caráter 
apostólico da diocese fundamentado na crença de que Tiago fora o seu fundador e ali se encontrava sepultado. Essas estratégias pelagianas também podem explicar porque, a redação B, Froilanus episcopus Ovetensis seja o primeiro nome citado e Cresconius Iriensis, o último. ${ }^{12}$

Ainda sobre a omissão do título apostólico relacionado a Iria, outro aspecto a ser pontuado é a censura feita por Leão IX a Cresconius no concílio de Reims, realizado em 1049, pelo fato deste prelado portar o título que, na perspectiva papal, só caberia ao bispo de Roma: "[...] excomunicatus est, etiam, Sancti Jacobi archiepiscopus Galliciensis, quia contra fas sibi vindicaret culmen Apostolici nominisn" (apud GARCIA GALLO, 1950, p. 311). Assim, a omissão do título no texto $B$ também poderia ser explicada como uma atitude de respeito da Sé ovetense frente ao papado. Mas por que foi mantida no texto $A$ ? A justificativa pode estar em certo conservadorismo presente no LP, que optou por não atualizar este aspecto, mesmo com a consolidação da preeminência papal nos séculos XII e XIII, ou foi uma opção para realçar o caráter apostólico da Sé de Compostela, que rivalizava com Toledo pela dignidade de Metropolitana.

A última divergência está nas formas Gomice Osimensis e Gomezius Occensis. Para Garcia Gallo a forma Osimensis é fruto de um erro do copista, pois a diocese de Osma só foi restaurada em 1088. Quanto à Occensis, ainda que a diocese de Oca só tenha sido restaurada em 1068, este título era usado pelo bispo de Burgos, que havia incorporado algumas regiões dessa diocese (1950, p. 349-350).

Segundo Reglero de la Fuente, nem todos os bispos do reino estiveram presentes em Coyanza, pois os prelados de Mondonhedo e de Munhoz-Sasamón não são listados nas atas (2006, p. 198). Este dado pode invalidar a minha interpretação de que a inclusão da listagem dos bispos presentes tinha um caráter simbólico, preservado nas duas redações. Mas o próprio autor destaca que não são encontradas notícias sobre bispos de Mondonhedo entre os anos 1047 a 1061 (2006, p. 198). Dessa forma, é possível inferir, face à ausência de notícias, que esta sede estivesse vacante quando da realização da reunião de Coyanza.

Quanto à diocese de Munhoz-Sasamón, além da ausência de notícias entre os anos de 1011-1043 e depois em 1059-1060 (REGLERO DE LA FUENTE, 2006, p. 198), como destaca Martin 
Visó (1999, p. 24-25), a referida sé foi de criação efêmera. Munhoz foi criada em função das transformações processadas durante os séculos iniciais do medievo, trasladada a Sasamón no século XI e, posteriormente, integrada a sé de Burgos. Como já havia sido suprimida quando foram feitas as cópias das atas, mesmo que houvesse um bispo dessa diocese presente, seu nome poderia ter sido omitido, a fim de atualizar o texto e manter a ideia de uma igreja castelhana-leonesa unida e presente na assembleia.

Por outro lado, os bispos de Palência e de Calahorra, dioceses então localizadas no reino de Pamplona, figuram entre os assistentes. Garcia Gallo justifica a presença destes prelados com o fato de Fernando I considerar o reino de Pamplona como seu após a batalha de Atapuerca, ainda que governado pelo seu sobrinho (1950, p. 354-356). Esta explicação, de caráter personalista, deve ser revista. O século XI é marcado por avanços e recuos nas fronteiras entre os reinos e não é possível falar de nações ou estados organizados. Além disso, as relações de poder entre as famílias reais, os optimates e os eclesiásticos eram dinâmicas e pontuadas tanto por conflitos como por ações de cooperação. Assim, a presença destes prelados em Coyanza pode ser explicada não como fruto do desejo pessoal de Fernando I, mas como resultante das estratégias de poder estabelecidas entre os reinos de Pamplona e Castela-Leão.

\section{Os decretos presentes nas versões $A$ e $B$ das atas de Coyanza}

$\mathrm{Na}$ perspectiva de Garcia Gallo, a Igreja castelhana-leonesa do século XI possuía autonomia face ao rei. Dessa forma, para o estudioso, todos os decretos relacionam-se a temas de competência da Igreja, seja por tratar de questões estritamente eclesiais, como liturgia, jejuns, vida religiosa, disciplina clerical etc., ou por seu caráter moral (1950, p. 361). Entretanto, para Mínguez Fernández, tais decretos indicam "[...] una manifestación de la soberanía regia que se extiende sobre la totalidad del reino" (2007, p. 26). De acordo com as atas da reunião, coube ao rei, à rainha e aos bispos a capacidade de legislar sobre temas gerais, que abarcavam vários 
aspectos e atores da sociedade, promulgando normas que deveriam ser seguidas nas regiões de Leão, Galícia, Astúrias, Portugal e Castela, incluindo os domínios senhoriais, eclesiásticos ou não. Fica patente, portanto, a preocupação de registrar uma relação estratégica de cooperação entre monarcas e bispos no reino castelhano-leonês durante o reinado de Fernando I e Sancha. Contudo, concordo com Mínguez Fernández: nas atas, há um reconhecimento da superioridade da autoridade régia face às demais, já que o que era legislado deveria ser seguido em todo o reino, por "omnes, tam maiores quam inferiores (texto A) / omnes maiores et minores (texto B)", o que incluía os bispos, como registrado nas duas redações das atas.

Ao analisar os cânones de Coyanza a partir deste outro pressuposto, podemos considerar que os primeiros seis decretos abordam temas relacionados estritamente à vida eclesiástica: a organização das comunidades de cônegos e de religiosos; o reforço da autoridade do bispo; a condenação à intervenção leiga; a indicação de como deveriam ser os utensílios e as vestes litúrgicas; o disciplinamento do comportamento, a aparência, sexualidade e os conhecimentos dos eclesiásticos; as instruções sobre a educação religiosa das crianças, sobre a necessária penitência pelos pecados, sobre a presença nas missas, e a proibição de convivência com judeus, seja partilhando a moradia ou uma refeição.

Do decreto sete ao dez, os assuntos tratados deixam o campo eclesiástico e regulam a prática jurídica, como normativas sobre testemunhos e as fontes de direito; as propriedades eclesiásticas e o destino da produção em terras sob litígio.

$\mathrm{O}$ decreto onze volta às questões religiosas e prescreve sobre os jejuns das sextas-feiras. Os dois últimos decretos retomam o tema jurídico. O doze dá detalhes sobre a função de refúgio das igrejas e o treze ordena que todos respeitem a justiça do rei.

Em um olhar de conjunto, verificamos, a partir dos temas tratados, que os decretos de Coyanza buscaram normatizar a vida dos eclesiásticos e dos leigos sob diversos aspectos, reafirmando, por um lado, o papel de liderança dos bispos, e, por outro, o fortalecimento da prática da justiça no âmbito do reino, em especial a justiça do rei. Pelos cânones, é possível identificar conflitos entre os bispos e o clero diocesano, os abades e os leigos. Também é possível concluir 
que os maiores do reino muitas vezes agiam com arbitrariedade em relação às populações locais e se recusavam a acatar as normativas reais. Em ambas as redações fica evidenciada uma harmonia entre a autoridade episcopal e real, mas essa relação também não é isenta de hierarquias, já que nos textos fica patente que as leis e a justiça foram estabelecidas e mantidas por reis e devem ser obedecidas por todos.

Dessa forma, independentemente dos fundamentos que regeram a redação dos cânones - tradições hispanas, influências de Cluny e de Roma - a normativa de Coyanza tinha como meta fortalecer a autoridade real, afirmar a liderança dos bispos em suas dioceses, constituir hierarquias entre os diferentes grupos, uniformizar práticas religiosas e condutas jurídicas.

$\mathrm{E}$ as diferenças de conteúdo entre as versões $A$ e $B$ ?

Garcia Gallo, que estuda as duas redações comparando-as às atas dos concílios visigóticos transmitidas pela Hispania e a outros textos do século XI, conclui seu trabalho afirmando que o texto $A$ possui uma redação mais próxima do que foram as decisões conciliares de Coyanza, enquanto que o texto $B$ apresenta uma redação reorganizada dos decretos, feita por algum jurista ou copista leonês na segunda metade do século XI ou início do XII, na qual os cânones figuram como um documento outorgado pelo rei e pela rainha. Dessa forma, a redação $A$ retrata, para Garcia Gallo, a versão conciliar, e a $B$, a real.

É importante destacar que, apesar de fundamentados e coerentes, os argumentos apresentados por Garcia Gallo estão assentados em uma perspectiva historiográfica que busca realçar o caráter "plenamente nacional" da Igreja castelhano-leonesa reunida na assembleia de Coyanza e a autonomia dos prelados face aos reis. Nesse sentido, o autor finaliza seu trabalho destacando que o referido concílio foi duplamente nacional. Primeiramente, porque foi convocado sem interferência externa, reunindo só personagens hispânicos para " [...] restaurar la vigencia de la legislación canónica genuinamente española contenida en la Hispania, o de las leyes patrias sobre a materia eclesiásticas", e, em segundo, "essencialmente eclesiástico", porque "[...] la presencia del rey y de los magnates del reino no supuso interferência alguna em sus tareas y mucho menos em sus decisiones" (1950, p. 630). 
Como parto de outros pressupostos para interpretar as atas de Coyanza, defendo que o estudo comparado das versões transmitidas não devem redundar na eleição de um texto mais próximo do original, mas na compreensão do sentido de tais redações. Dessa forma, as divergências entre $A$ e $B$ não significam, necessariamente, que uma das redações é a mais verdadeira e podem ser explicadas, por um lado, por erros e/ ou omissões dos copistas, mas, por outro, pelo local social em que foram transmitidas e pelo papel ocupado pelo documento ao dar sentido, legitimar e hierarquizar certas práticas sociais.

A redação $A$, que apresenta os bispos como narradores, normatiza essencialmente sobre a vida clerical e canônica, tanto secular quanto regular. ${ }^{13}$ Assim, nessa versão, são incluídos aspectos relacionados à função clerical, como o batismo e a crisma, a opção pelo seguimento da regra de Isidoro ou de S. Bento e a ordenação de monges. ${ }^{14}$ A presença de normativas para a vida canônica em $A$, que não figura em $B$, faz sentido, já que os textos que compõem esta coletânea foram copiados na catedral de Coimbra, onde existia um cabido desde a restauração da diocese no final do século XI. Assim, textos reguladores da vida dos cônegos eram necessários. O próprio LP contém outros materiais que normatizam a vida canônica, como o diploma de n. 627, que contém as medidas tomadas pelo bispo D. Gonçalo quanto ao número de cônegos, às atribuições do deão e à separação do patrimônio episcopal e capitular (MORUJÃO, 2006, p. 87). O narrador de A é o conjunto de bispos e está preocupado, sobretudo, em instituir normas para os clérigos, legitimando a autoridade episcopal, instituindo hierarquias nas dioceses e destacando a harmonia com os reis.

O tom da redação de $B$, que tem como promulgador o rei e sua esposa, é de instituir normas para todos os setores sociais. Assim, enquanto o texto $A$ do cânone II trata somente da vida canônica, o $B$ normatiza sobre o monacato masculino e feminino, o que explica que nesta versão só figure a opção pela regra beneditina. Dessa forma, nesta redação, há uma clara tentativa de distinguir as normativas voltadas para as comunidades monásticas face às canônicas. Por isso, na redação $B$, os termos abbates e monachi presentes nos títulos IV e V de $A$ são substituídos por archidiaconi e presbiteri, fazendo uma evidente referência aos clérigos, distinguindo-os dos religiosos. Em 
B o objetivo é legitimar uma dada ordem social, com suas hierarquias, tendo como figuras principais de autoridade o rei e a rainha.

\section{Considerações finais}

Para o estudo do que foi a assembleia de Coyanza, só possuímos como fontes diretas de pesquisa as duas versões das atas transmitidas pelos manuscritos. Assim, sobre esta reunião foram propostas muitas hipóteses, que foram fundamentadas, mormente, em perspectivas dicotômicas, opondo as tradições hispanas aos influxos externos ou o rei à igreja "nacional". Tais reflexões revelam mais sobre o contexto de produção dos trabalhos e dos posicionamentos políticos de seus autores do que do que aconteceu em coyanaza.

Neste artigo, portanto, o que foi a assembleia de Coyanza deixou de ser o foco. A meta foi compreender e analisar os registros sobre este concílio que foram difundidos por meio de duas redações. Para tanto, como sugere Sanz Sancho (1998, p. 83), rompi com as interpretações dicotômicas e renunciei a busca pelas atas "verdadeiras". Assim, a análise voltou-se para a discussão de como a transmissão das atas de Coyanza foi dotada de sentidos e funcionou estrategicamente em distintos contextos sociais.

Mais do que tomadas como testemunhos fiéis de um acontecimento, as atas são consideradas materiais centrais para discutir a cristalização, a transmissão e o uso de memórias sobre tal reunião, a fim de percebermos as relações de poder e as normativas nos séculos XI e XII em Castela e Leão.

Por meio da análise, concluímos que as duas redações das atas de Coyanza se explicam pelos grupos com as quais dialogaram e o meio social em que foram copiadas. Elas apresentam aspectos que propiciam a compreensão das relações de poder e o alvo das normativas em Castela e Leão nos séculos XI e XII. Assim, em ambas as redações percebe-se a preocupação em reafirmar a autoridade real, por meio, sobretudo, da prática da justiça. Tal esforço relaciona-se, por um lado, às relações de poder entre monarcas e optimates, conflitantes em diversos momentos, e, por outro, à própria necessidade de legitimar as práticas jurídicas e normas pro- 
postas nas atas, que têm como alvos todos os habitantes do reino. Verifica-se, também, o reforço ao papel de líder que deveria ser ocupado pelos prelados nas dioceses, que pode vincular-se a tensões internas dos episcopados, que opunham bispos a cônegos e clérigos de todos os graus, e a externas com os leigos, em especial os "maiores". O realce dado à harmonia entre bispos e reis é outro aspecto digno de nota e pode significar uma reconfiguração de forças em um contexto de expansão territorial e maior fluxo de riquezas.

\title{
NORMS AND POWER RELATIONS IN THE ACTS OF THE COUNCIL OF COYANZA
}

\begin{abstract}
The Council of Coyanza was assembled in the middle of the eleventh century in the diocese of Oviedo, during the reign of Fernando I and Sancha, in Castile-Leon. This assembly is considered as one of the most important in the Iberian peninsula gathered during the Middle Ages by many authors, It is quoted in several papers, but since 1950 no specific and systematic studies on its records were made. These minutes were transmitted from different manuscripts, which contains two distinct redactions, differed by formal or content, which provides to the historian to discuss issues related to the circulation and transmission of such material. In this article, based on the analysis of such proceedings and on historiographical reflections already produced about such meeting, I discuss aspects of normalization in the Kingdom Castilian-Leonese in the period and its manuscript's diffusion, relating these to the power relations.
\end{abstract}

Keywords: Council of Coyanza. Kingdom of Castile-Leon. Norms. Power. Manuscript's diffusion.

\section{Notas}

${ }^{1}$ Os reinos de Castela e Leão estiveram unidos e separados em diversos períodos entre os séculos XI e XIII, até a união definitiva, em 1230. Neste momento, como será abordado no decorrer do texto, tais reinos encontravam-se unidos.

${ }^{2}$ Neste artigo são retomadas, revistas e ampliadas ideias que apresentei em dois textos já publicados: O Concílio de Coyanza: algumas reflexões sobre uma assembleia castethano-leonesa, apresentado no XXVI Simpósio Nacional de História da Anpuh e disponível em http://www.snh2011.anpuh.org/resources/anais/14/1312308920_

Anos 90, Porto Alegre, v. 20, n. 38, p. 103-126, dez. 2013 


\section{Andreia Cristina Lopes Frazão da Silva}

ARQUIVO_AndreiaCLFrazaoDaSilva_Anpuh_2011.pdf e Reflexões sobre monacato, gênero e poder: uma leitura dos cânones do Concílio de Coyanza, artigo publicado na revista Métis e também disponível on line: www.ucs.br/etc/revistas/index. $\mathrm{php} / \mathrm{metis} /$ article/viewArticle/1686.

${ }^{3}$ Não tivemos acesso a esta obra.

${ }^{4}$ O LP é uma compilação de 663 diplomas provenientes da região de Coimbra datados de meados do século IX a início do século XIII, reunidos e transcritos entre os séculos XII e XIII no scriptorium da Sé de Coimbra (BURNS, 2001, p. 87). Dentre estes encontra-se uma cópia dos decretos de Coyanza.

5 "Hoc decretum factum fuit in concilio domni Fernandi regis et sue conjugis regine, domne Sancie, in urbe Cogianca. Et adduxit, inde, illud Randulfus, presbiter de acisterio Vaccariza, pro memoria posteris".

${ }^{6}$ Optamos pelo uso do termo Pamplona ao invés de Navarra visto que os seus reis, até meados do século XII, apresentam-se como "rex in Pampilona".

7 Garcia herdou o Reino de Pamplona, também denominado Reino de Nájera; Ramiro, Aragão e Gonzalo, os condados de Sobrarbe e Ribagorza.

${ }^{8} \mathrm{O}$ outro argumento levantado por Garcia Gallo é a presença, no texto B, das expressões "ad restaurationem nostrae Christianitatis" e "cum episcopis, et abbatibus et totius nostri regni optimatibus". Como dentre os presentes havia bispos de Navarra e como a região só foi anexada ao Reino de Castela-Leão após Atapuerca, para o autor o concílio só poderia ter sido realizado após 1055 (1950, p. 353). Não concordo com esse argumento, pois estas referências à "nossa cristandade" e "nosso reino" poderiam ter sido introduzidas pelos copistas, como uma atualização, quando, efetivamente as áreas de Navarra haviam sido anexadas; ou seja, estas expressões poderiam não figurar na versão primeira do texto.

${ }^{9}$ Garcia Gallo sintetiza tais debates em seu texto (1950, p.361-366).

${ }^{10}$ Sanz Sancho publicou uma síntese sobre esse debate, no qual apresenta a referência completa dos trabalhos dos autores citados (1998).

${ }^{11}$ Se acatarmos a referência presente em LP, citada na nota 4 , além dos maiorais do reino, estiveram presentes ao concílio presbíteros, diáconos, priores etc.

${ }^{12}$ Faz-se importante lembrar que Pelayo foi contemporâneo de Diego Gelmírez. Durante o governo deste prelado, a diocese compostelana expandiu-se, tornando-se um arcebispado.

${ }^{13}$ Neste sentido, os termos abade e monges presentes nos cânones se referem aos cônegos, não aos monges.

${ }^{14}$ Ver nota anterior. 


\section{Referências}

ALONSO ÁlVAREZ, Raquel. Patria uallata asperitate moncium. Pelayo de Oviedo, el archa de las relíquias y la creación de una topografía regia. Locus Amoenvs, Barcelona, n. 9, p. 17-29, 2007-2008.

AYALA MARTINEZ, Carlos de. Sacerdocio em la España Altomedieval: Iglesia y poder político en el Occidente peninsular, siglos VII-XII. Madrid: Silex, 2008.

BANGO TORVISO, Isidro Gonzalo. La renovación del tesoro sagrado a partir del concilio de Coyanza y el taller real de orfebrería de León. El Arca Santa de Oviedo (1072). Anales de historia del arte, Madri, n. Extra 2, p. 11-68, 2011.

BISHKO, Charles J. Fernando I and the Origins of the Leonese-Castilian Alliance With Cluny. Disponível em: libro.uca.edu/frontier/bishko2.htm. Acesso em: 09 marzo 2011.

BURNS, Robert I. Livro preto: Cartulário da Sé de Coimbra. Edição crítica, texto integral. Review. The Catholic Historical Review, Washington, v. 87, n. 1, p. 87, 2001. CALLEJA PUERTA, Miguel. La Catedral de Oviedo como centro de conservación de documentos en la alta Edad Media. In: V.V.A.A. Estudos em homenagem ao Professor Doutor José Marques. Porto: Departamento de Ciências e Técnicas do Património e Departamento de História da Faculdade de Letras da Universidade do Porto, 4 v. V. 4, 2006. p. 179-191.

CARRASCO, Juan. Los espacios políticos de la Península Ibérica a mediados del siglo XI. In: IGLESIA DUARTE, José Ignacio de la (Coord.). SEMANA DE ESTUDIOS MEDIEVALES, 15., 2004, Tricio y San Millán de la Cogolla. Actas... Logroño: Instituto de Estudios Riojanos, 2005. p. 93-118.

DÍAZ DE GARAYO, Ernesto Pastor. Los testimonios escritos del sector meridional de Castilla (siglos X-XI): ensayo de crítica documental. Historia, instituciones, documentos, Sevilha, n. 24, p. 355-380, 1997.

FERNÁNDEZ CONDE, Francisco Javier. El Libro de los Testamentos de la catedral de Oviedo. Roma: Iglesia Nacional Española, 1971.

FERNÁNDEZ DEL TORCO, José Maldonado y. Las relaciones entre el Derecho canónico y el Derecho secular en los concilios españoles del siglo XI. Anuario de bistoria del derecho español, Madri, n. 14, p. 227-381, 1943.

GARCÍA DE CORTÁZAR, José Angel. El dominio del monasterio de San Millán de la Cogolla (siglos X al XIII). Introducción a la historia rural de Castilla altomedieval, Salamanca, Ediciones Universidad de Salamanca, 1969.

Anos 90, Porto Alegre, v. 20, n. 38, p. 103-126, dez. 2013 


\section{Andreia Cristina Lopes Frazão da Silva}

GARCIA GALLO, Alfonso. El concílio de Coyanza. Anuario de Historia del Derecho Español, Madri, n. 20, p. 275-633, 1950.

GARCÍA TURZA, Francisco Javier. San Millán de la Cogolla en los umbrales de la crisis: 1200-1300. In: GIL-DÍEZ USANDIZAGA, Ignacio (Coord.). Jornadas de arte y patrimônio regional, 6., 1998, San Millán de la Cogolla. Actas... Logroño: Instituto de Estudios Riojanos, 2000. p. 27-46.

LINAGE CONDE, José Antonio. El papel de Andalucía en la benedictinización del monacato peninsular. En la España medieval, Madri, n. 2, p. 583-594,1982.

. En torno a la benedictinización: La recepción de la Regla de San Benito en le monacato de la península ibérica a través de Leyre y aledaños. Príncipe de Viana, Pamplona, v. 46, n.174, p. 57-92, 1985.

LÓPEZ ALSINA, Fernando. El encuadramiento eclesiástico como espacio de poder: de la parroquia al obispado. In: IGLESIA DUARTE, José Ignacio de la; MARTÍN RODRÍGUEZ, José Luis (Coord.). Semana de Estudios Medievales, 12. 2001, Nájera. Actas... Logroño: Instituto de Estudios Riojanos, 2002. p. 425-457.

MARTÍN VISO, Iñaki. Organización episcopal y poder entre la Antiguedad tardía y el Medievo (siglos V-XI): las sedes de Calahorra, Oca y Osma. Iberia. Revista de la Antigüedad, Logroño, n. 2, p. 151-190, 1999.

MARTÍNEZ, Díez Gonzalo. Coyanza, 1055. In: ALDEA VAQUERO, Quintín; MARIN MARTINEZ, Tomás; VIVES GATELL, José. Diccionario de Historia Ecclesiastica de España. Madrid: Consejo Superior de Investigaciones Cientificas, 5v. v. 2, 1973. p. 543-544.

MENJOT, D. A historiografia da Idade Média espanhola: da história da diferença à história das diferenças. ALMEIDA, N. de B. ; CANDIDO DA SILVA, M. (Orgs). Poder e construção social na Idade Média: História e Historiografia. Goiânia: UFG, 2011. p. 211-291.

MÍNGUEZ FERNÁNDEZ, José María. Pervivencia y transformaciones de la concepción y práctica del poder en el Reino de León (siglos X Y XI). Studia Historica. Historia Medieval, Salamanca, n. 25, p. 15-65, 2007.

MORUJÃO, Maria do Rosário Barbosa. Os estatutos do cabido da Sé de Coimbra de 1454. In: V.V.A.A. Estudos em homenagem ao Professor Doutor José Marques. Porto: Departamento de Ciências e Técnicas do Património e Departamento de História da Faculdade de Letras da Universidade do Porto, 2006. 4 v. V. 4, p. 85-108.

PÉREZ DE CIRIZA, Jesús Miguel Fortún. Monjes y obispos: la Iglesia en el reinado de García Sánchez III el de Nájera. In: IGLESIA DUARTE, José Ignacio de la (Coord.).

Anos 90, Porto Alegre, v. 20, n. 38, p. 103-126, dez. 2013 
REGLERO DE LA FUENTE, Carlos Manuel. Los obispos y sus sedes en los reinos hispánicos occidentales. In: SEMANA DE ESTUDIOS MEDIEVALES. 32., 2005, Estella. Actas... Pamplona: Gobierno de Navarra, 2006. p. 195-288.

SÁNCHEZ CANDEIRA, Alfonso. Castilla y León en el siglo XI. Estudio del reinado de Fernando I. Madrid: Real Academia de la Historia, 1999. SANTOS COCO, Francisco. (Ed.). Historia Silense. Madrid: Rivadeneyra,1921. SANZ SANCHO, Iluminado. Notas sobre la politíca religiosa en tiempos del rey Fernando I de León y Castilla. Cuadernos de Historia Medieval, Madri, n. 1, p. 73-109, 1998.

SEMANA DE ESTUDIOS MEDIEVALES, n.15, 2004, Tricio y San Millán de la Cogolla. Actas... Logroño: Instituto de Estudios Riojanos, p. 191-252, 2005.

TEJADA Y RAMIRO, Juan (Ed.). Concílio de Coyanza. In: Colección de cánones y de todos los concilios de la Iglesia de España y de América. Madrid: Imprenta de D. Pedro Montero, 5t. T. 3, parte 2, p. 95-101, 1861.

VAZQUEZ DE PARGA, Luis. El fuero de León, notas y avance de una edición crítica. Anuario de Historia del derecho español, Madri, n. XV, p. 464- 498, 1944.

Recebido em: 29 de junho de 2013. Aprovado em: 02 de agosto de 2013. 